\title{
DIFFERENCE OF GAZE: STUDY OF THEMATIC PATTERNS OF THE WRITINGS OF UMA PARAMESWARAN AND RUPI KAUR
}

\section{Dr. Divyeshkumar Devendraprasad Bhatt.}

\begin{abstract}
Canada, the land of multiculturalism, is the land of greater diversities and the specter of vivid cultures and people from diverse roots who have made it their home. The entire cultural scenario of Canadian culture presents the multi faceted cultural fusions. Even etymologically, the term 'Canada' itself has the roots in St. Lawrence Iroquoian word kanata which means 'village' or 'settlement'. It is one of the world's most ethnically diverse and multicultural nations. Since the establishment of the European settlement by Samuel de Chaplain in 1603, Canada has remained a queer attraction and destination for the people of foreign lands all across the world for one or another reasons. Beginning with the French and English dominative influences, Canadian artistic and cultural pool has evolved its own unique artistic legacies through the fusion and co-existence of mosaic variety of different cultures of people who practiced their own traditions along with the impact of their life stories on the Canadian lands. The works of South Asian creative writers display a rich arena of diverse sensibilities. In the penning practices of some of them one finds a great attachment with their home land and the strong connect with the native milieu and the avid struggles in the land far from the home site finds clear expression. Such writings are critically branded as the Diaspora Writings. This paper tries to evaluate on the compare and contrast basis the thematic patterns of the two generations of Indian origin creative writers Uma Parameswaran and Rupi Kaur. The researcher finds a queer interest in weighing the ways both the female creative writers' unique style of dealing with their feministic approach in that the researcher finds clearly embossed the societal versus individual gaze. In particular, where the senior one tries to explore the foreign terrains with the strong attachments with the home land and her relations with the other members of society, the junior remains confided within individualistic one-to-one relations with a liberalistic vein from the male dominance.
\end{abstract}

Key words:

Canadian Literature, bilingualism, multiculturalism, feminist approach, immigrant voices 
Canada, the land of multiculturalism, is the land of greater diversities and the specter of vivid cultures and people from diverse roots who have made it their home. The entire cultural scenario of Canadian culture presents the multi faceted cultural fusions. Even etymologically, the term 'Canada' itself has the roots in St. Lawrence Iroquoian word Kanata which means 'village' or 'settlement'. It is one of the world's most ethnically diverse and multicultural nations. Since the establishment of the European settlement by Samuel de Chaplain in 1603, Canada has remained a queer attraction and destination for the people of foreign lands all across the world for one or another reasons. Beginning with the French and English dominative influences, Canadian artistic and cultural pool has evolved its own unique artistic legacies through the fusion and co-existence of "Mosaic and Salad Bowl" variety of different cultures of people who practiced their own traditions along with the impact of their life stories on the Canadian lands.

Canadian literary canvass is full of different shades. If one begins historically, the story of Canadian Domain of arts begins with the French and English hegemony and native aboriginal arts. The initial bilingualism was replaced with multiculturalism with the political adoption of the policies of 'Multiculturalism' in 1971. This gave ample scope and room to the literature of the immigrants to flourish on the Canadian horizons. This literature was based on the immigrants' sensibilities towards the land they had made their home along with their ailments towards their motherland where lied/crept their roots. The major themes of this class of writers can be devised into the several categories, both in prose, poetry or plays, such as their struggles of settlement in the new land and appeasement with the new identities, their struggles to keep the relations alive with that of the native societies and traditions at home, their failures and success and so on.

In many ways this class of literature has enriched the multicultural scenario of Canadian literature. The class of the writers, who are basically immigrants and who have moved to this part of the world in order to settle down here, represent diverse traditional backgrounds. In this group fall the south Asians (Indians, Sri Lankans), the Europeans, the Africans and their writings equally represent the links with the traditions of their homeland with a strong connect with the Canadian soil and life style. As Staines remarks,

"the Canadian preference for a mosaic structure in which all the ethnic and social regions retain their distinctness is central to an understanding of the nation. As a country, Canada is not only a mosaic of ethnic cultures but also a mosaic of regions, each with its own sense of identity; the nation, therefore, exists in dialectic of regional and ethnic tensions." (Stains)

As the generations of immigrants get rooted, their sensibilities and ways and visions to look at life, too find greater diversification. It may simply be noted that while the earlier generations in their initial phases struggled and strove for their identity in the new land and even being in the foreign land searched their bindings with their home-land, the new generation is quite free from this distance consciousness and has assimilated with the land without being conscious of it. What attract the new generation are the issues more open and applicable to the standards of life.

This paper tries to look at the thematic patterns in the works of two Canada based Indian Poetesses who represent two consecutive generations and tries to weigh their works 


\section{Divyeshkumar Bhatt / Page 212-218}

comparatively in the context of past and present. Uma Parameswaran -- poet, playwright, and short-story writer -- was born in Madras and grew up in Jabalpur, India. Currently she is a professor of English at The University of Winnipeg. Since settling in Canada, Parameswaran has devoted much of her writing and efforts in the literary field to creating an identifiable South Asian Canadian diaspora. Rupi Kaur, the second poetess under our focus of study, is a Toranto based poet who is famous for her new verse which she prefers to write in lower case weaving the subjects like sexual abuse, love, trauma, loss, and healing through poetry. Her poetry addresses the issues of equality and gender bias in the society and voices a retaliating tone. There is not a bit reference to the concerns of rootlessness or striving to make a connecting rig to the homeland as do we find in her senior counterpart.

Kaur's work exhibits her personal struggles when she was shifted to Canada as a part of family immigration from Punjab, India to Toronto. Initially she faced language troubles and unable to speak English, unlike other children in class, Kaur, as she herself confesses, she ended up an introvert spending and preferring most of time alone. At many places in her writings, she rings this note in commanding tones to her readers (mostly her imaginative address remains focused on the women readers):

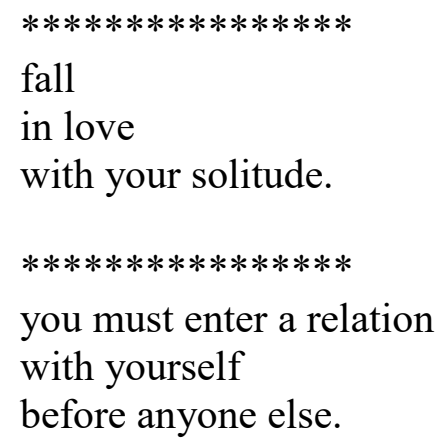

She says, in one of her interviews, "I always wrote stories but I do remember a particular moment in middle school where I became passionate about essay writing. I won the speech competition in class and I always say this was my first 'spoken word performance'. It was the first time I got on stage and recited something. I fell in love with the stage at the age of 12." (Kaur, How to Be A Woman)

Both the poetesses though their major thematic patterns are different share common biting stances for their feministic approaches and for the discriminations extended towards the South-Asian communities from colour or racial grounds. Uma Parameswaran, in her Dear Deedi, My Sister, voices this:

Have we come from the Niger and Luzon

From the Antilles and Hong Kong

To these vast empty spaces

Only to see our young one' s faces slapped

By unthinking scorn, unfeeling barbs 
Towards Excellence: An Indexed, Refereed \& Peer Reviewed Journal of Higher Education / Dr.

Divyeshkumar Bhatt / Page 212-218

From closed fists and closed hearts?

(Parameswaran, Dear Deedi, My Sister)

Rupi Kaur is fine with her own style of rebuke to those who mind the colour as taunting criterion in their weighing of concepts of 'Beauty'.

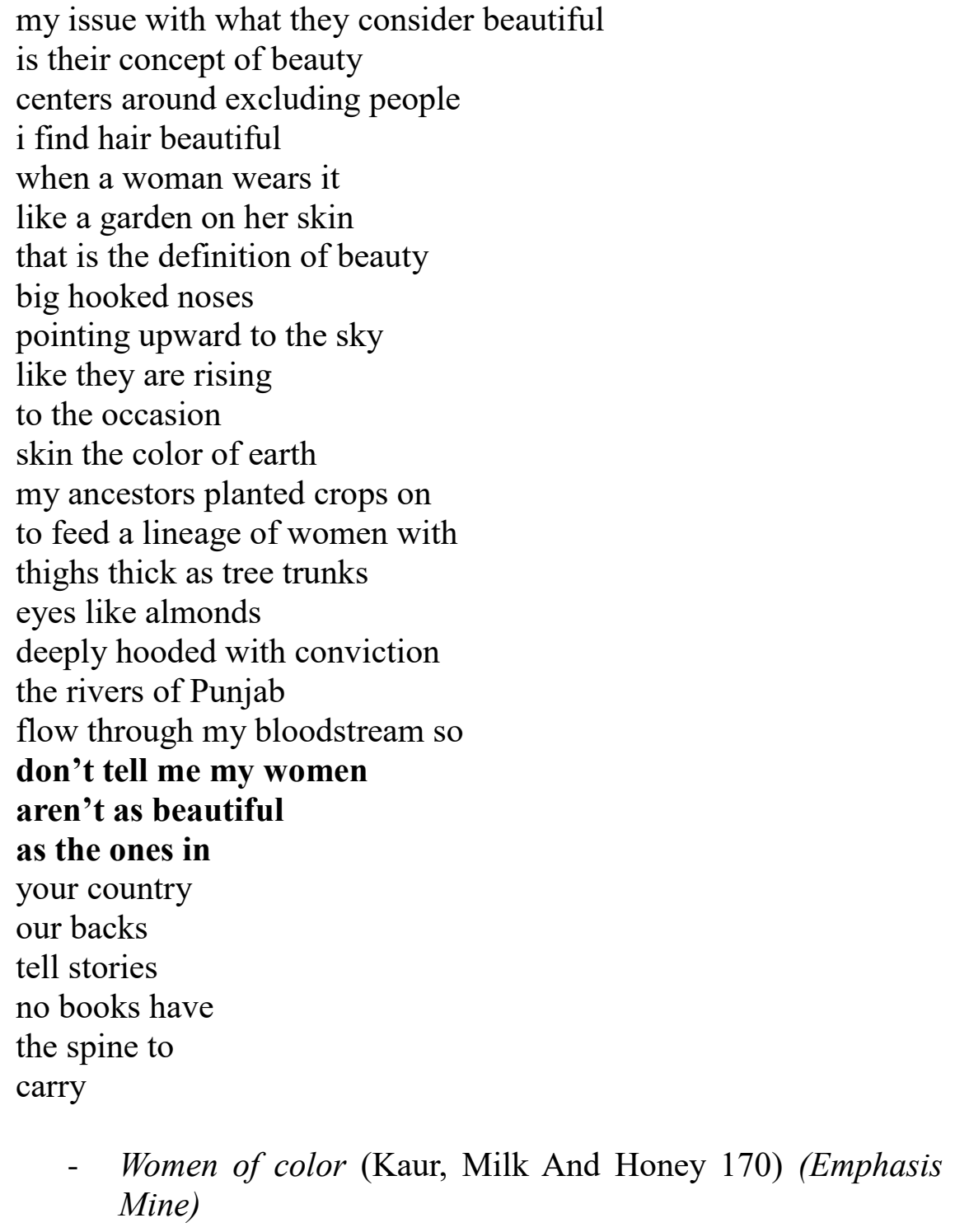

One clearly finds the point that while Uma Parmeshwaran tackles the point mildly through her artistic consciousness as being in the foreign land i.e. being in their land, whereas Kaur takes the stance of equality and in a word of open rights and issues her command to 'them' not to commit mistake considering her woman of any lesser beauty. And taking the point further she advises the class of 'Women of Color' that:

accept yourself 
Towards Excellence: An Indexed, Refereed \& Peer Reviewed Journal of Higher Education / Dr.

Divyeshkumar Bhatt / Page 212-218

as you were designed (Kaur, Milk And Honey 172)

Uma Parameswaran's Dear Deedi, My Sister describes the life and hardships of immigrants in Canada through a variety of characters and the letters written between Sapna in Canada and her sister in India. As Sapna muses,

Here too women suffer, dear Deedi, for being women.

The burdens are different but the pain is the

same. (Parameswaran, Dear Deedi, My Sister)

The same concerns and pains of being woman are also shared by Rupi Kaur. Uma Parameswaran asserts in a meek and submissive tone that in the life of a woman the pains have an invariable place whether she is in India or somewhere else, the pains of being woman occupy as essential luggage in the journey of life of a woman. Kaur too has the same pangs of being woman but in her poetic creation she is far away from the idea of giving in to the situation. Rather she in her as usual commanding tone would ask her 'Sisters' to realize their own potentials and to have a new view for life:

\author{
i want to apologize to all the women \\ $i$ have called pretty \\ before i've called them intelligent or brave \\ $i$ am sorry $i$ made it sound as though \\ something as simple as what you're born with \\ is the most you have to be proud of when your \\ spirit has crushed mountains \\ from now on i will say things like
}

you are resilient or you are extraordinary

not because i didn't think you are pretty

but because you are so much more than that. (Kaur, Milk And Honey 179) (Emphasis mine)

In her another major work Trishanku: A Cycle of Voices, Uma has invested the mythological figure of Trishanku in the very title i.e. the concept of being and belonging nowhere as the central theme of her poems in the collection. The idea here suggests the condition and the plight of the aspirant migrants in the foreign lands. Basically, these are the class of people who leave their mother land in search of their utopian heavens with the utmost commitments of hard work and convictions to bear any kind of hardships as the toll for their desired happiness. They even readily bear the pains of getting uprooted from the motherland. The only thing that keeps him/her up, is the prosperity in the form of material rewards, a slightly elevated status back at home and self-respect earned through the process as being counted as success. Uma Parameshwran clearly notes that though the migrant succeeds in these criteria to certain measures, in the process the loss is greater than his/her gains. He/she finds a sound feelings of being uprooted which haunts him/her even in his/her dreams too. In this long narrative poem fifteen different voices offer immigrants' experiences. The entire poem documents the nostalgic sensations of those who have settled down in there, their struggles to be adapted to the new environment, their ethno-cultural issues and their trying to create their own 
Towards Excellence: An Indexed, Refereed \& Peer Reviewed Journal of Higher Education / Dr.

\title{
Divyeshkumar Bhatt / Page 212-218
}

circles in the foreign land. Just as the mythical Trishanku, they find themselves nowhere:

I have been there, my brother,

The land is green but my heart was barren,

Warm are the people but my heart was lonely,

Money flows in rivers but my heart was dry,

Bereft of want and tensions

Bereft of sorrow and pain

Bereft of comradeship

My heart lost its voice, my brother.

It is not the land for you and me. (Parameswaran, Trishanku and Other Writings 51)

Kaur, in her penning practices amplifies her self-love, her intimate love relations, break ups and her own rehabilitation and recovery from the shocks and even touches the subject of being sexually exploited as a child. But in all this, her tone remains that of didactic to her fellow sisters not to be meek or submissive. Her empowerment drive never loses its strength as she puts her finger on specific vulnerabilities and addresses them directly. For her weaknesses are the ladders to rise and incompleteness is the real strength of being complete:

\author{
if you were born with \\ the weaknesses to fall \\ you were born with \\ the strength to rise (Kaur, Milk And Honey)
}

Her sturdiness reflects readily in one of her responses to the question "How do you feel your identity as a woman of color influences your poetry?," in an interview with Rachel Grate:

i think who you are is everything. and so when who you are is invisible, butchered, undesirable, and so on, it can do a lot of damage. so being a brown woman growing up in the west, where the ideal woman was white, sent me on a terrifying journey.

i was already doubting who i was because ... women like me were not represented at all. anywhere. so i had no one to look up to. that looked like me. that had parents like mine. that spoke my language. that carried my strong punjabi features. it all happens subconsciously. you are convinced you are ugly. and even if you know you're beautiful, you think you cannot be beautiful enough.

those experiences pushed my work. i was forced to ask myself the difficult questions. $\mathrm{i}$ had to look at myself in the mirror, make a list of things i disliked about me and write about those so i could learn and figure out ways to fall in love with them. so that i could show other brown women why we need to celebrate the things that make us unique. (Kaur, http://hellogiggles.com/feminist-poet-rupi-kaur/)

Both Uma Parmeshwaran and Rupi Kaur share same identity crisis and struggles for 
Towards Excellence: An Indexed, Refereed \& Peer Reviewed Journal of Higher Education / Dr.

\section{Divyeshkumar Bhatt / Page 212-218}

acceptance and recognitions in the alien land. Still the stance with which both of them address and react to it finds a conspicuous difference, while Uma's appeals bear mild and societal somberness, Kaur's reactions are volcanic in the tone of slapping back in the face of the discriminators, rather than just being pain sucker without any say.

\section{Works Cited:}

Kaur, Rupi. How to Be A Woman, Puja Pillai. 5 June 2016.

Kaur, Rupi. http://hellogiggles.com/feminist-poet-rupi-kaur/ Rachel Grate. 12 January 2015.

—. Milk And Honey. Kansas city, Missouri: Andrews McMeel Publishig, 2015.

Parameswaran, Uma. Dear Deedi, My Sister. Alexander Street Press, 2003.

—. Trishanku and Other Writings. Delhi: Prestige, 1998.

Stains, David. The Canadian Imagination. Mssachusetts: Harvard University Press, 1977.

\section{Dr. Divyeshkumar Devendraprasad Bhatt. Assistant Professor Mahadev Desai Gramseva Mahavidyalaya, Gujarat Vidyapith, Sadra.}

